\title{
EL DERECHO A LAS RELACIONES PERSONALES ENTRE LOS NIETOS Y SUS ABUELOS. UNA APROXIMACIÓN SOCIO-JURÍDICA*
}

\author{
Jorge GRACIA IBÁÑ̃Z \\ DOCTOR EN DERECHO \\ INVESTIGADOR DEL LABORATORIO DE SOCIOLOGÍA JURÍDICA \\ DE LA UNIVERSIDAD DE ZARAGOZA
}

SUMARIO: I. Introducción. II. Transformaciones del rol social y familiar de los abuelos y abuelas. III. El régimen legal del derecho a las relaciones personales entre abuelos y nietos en el ordenamiento jurídico español. III.r. Finalidad de la ley. III.2. Alcance y contenido esencial del derecho a las relaciones personales entre abuelos y nietos. III.3. Naturaleza del derecho. III.4. Contenido, ejercicio y límites del derecho. IV. Conclusiones. V. Bibliografía.

RESUMEN: Las transformaciones experimentadas en la sociedad española por la familia en las últimas décadas han afectado también a las personas mayores produciéndose un estrechamiento de las relaciones entre abuelos y nietos. En el presente artículo se analiza, desde la perspectiva de la sociología jurídica, el reconocimiento explícito del derecho a las relaciones personales entre abuelos y nietos y su regulación en el ordenamiento jurídico español a partir de las reformas introducidas por la Ley 42/2003, de 2I de noviembre. Se lleva a cabo una aproximación a la norma destacando los aspectos sociológicos implícitos en la misma y la importancia otorgada al mantenimiento de dichas relaciones personales en el interés superior de los menores.

PALABRAS ClAVE: personas mayores, derecho de familia, derecho a las relaciones personales entre abuelos y nietos, interés superior del menor, análisis socio-jurídico.

ABSTRACT: Social changes affecting Spanish families during the last decades have also affected elder people whose relationships with their grandchildren had been strengthened. This article focuses on the enactment of the rights of personal relationship between grandparents and their grandchildren by the Act 42/2003 from a socio-legal perspective. An approach to the current legal regulation pointing out the inherent sociological aspects and the importance of the preservation of the personal relationship in the best interests of the children is examined.

KEYWORDS: elders, family law, grandparent and grandchildren's personal relationship rights, best interests of the child, socio- legal analysis.

\footnotetext{
* Este trabajo se enmarca dentro del Proyecto Consolider-Ingenio 2010 «El tiempo de los derechos» (CSD 20080 0007 ). Se trata de una re-elaboración y actualización de la comunicación presentada en el Congreso Ruptura familiar y responsabilidad parental organizado por el Laboratorio de Sociología Jurídica en octubre de 2009 en Zaragoza.
} 


\section{Introducción}

En los últimos tiempos, acompañando a otras transformaciones experimentadas en el seno de la familia, el papel de los abuelos y las abuelas ha experimentado una importante mudanza. Las relaciones abuelos/nietos parecen haberse estrechado, ampliado en su contenido, cambiado de significado. En este nuevo contexto social surge la necesidad de regular el derecho a las relaciones personales entre los nietos y nietas y sus abuelos y abuelas. Esta regulación resulta pertinente si tenemos en cuenta que, en muchas ocasiones, los abuelos no actúan como parientes ajenos y distantes sino como protagonistas destacados y más o menos directos en el proceso de socialización de sus nietos. Los importantes lazos personales y emocionales que suelen existir, hacen que el mantenimiento de estas relaciones merezca ser tenido en cuenta por el derecho con el fin de garantizar el bienestar y el adecuado desarrollo personal y emocional de los menores especialmente ante situaciones de conflicto grave, crisis y ruptura familiar.

La necesidad de reconocer un derecho a la relación personal entre abuelos y nietos, aunque construida hasta ese momento a través de la jurisprudencia, culmina legislativamente en la reforma del Código Civil (en adelante CC) y de la Ley de Enjuiciamiento Civil (en adelante LEC) en materia de relaciones familiares de los nietos con los abuelos operada mediante la Ley 42/2003, de 2I de noviembre (BOE 280, 22 de noviembre de 2003).

En este artículo, pretendemos realizar una aproximación al tema desde el prisma y la perspectiva de la sociología jurídica. Se trata de una cuestión que proporciona un interesante ejemplo de la compleja mezcla de procesos socioculturales, económicos y culturales que generan las políticas sociales y del equilibrio entre poder legislativo y judicial que habitualmente se combina en su concreción ${ }^{\mathrm{I}}$. Para ello, comenzaremos por considerar específicamente el rol de los abuelos y abuelas en relación con sus nietos y nietas y las transformaciones del mismo en el seno de las familias; después, nos centraremos en la regulación legal específica en el ordenamiento jurídico español del derecho a las relaciones familiares de los abuelos con sus nietos. No se trata tanto de abordar un análisis dogmático del ordenamiento jurídico en este punto -aunque se analice la solución prevista en sus elementos fundamentales- sino de explorar las razones ancladas en el cambio social experimentado por el rol de los abuelos y abuelas que, inserto en el cambio más amplio experimentado por las familias como institución social, dan sentido a la regulación actual y a la aplicación judicial de las mismas en los términos que analizaremos.

\section{Transformaciones del rol social y familiar de los abuelos y abuelas}

Aunque en un análisis apresurado podríamos pensar que el profundo cambio social experimentado por sociedades como la española ha ido debilitando la institución familiar, de una observación más detenida y profunda se deduce que, si bien la familia ha ido transformándose, goza todavía de muy buena salud. En este sentido, el sociólogo Gerardo Meil advierte un aparentemente contradictorio reforzamiento del control social sobre las dinámicas de poder que se ejercen en la familia anteponiendo los derechos individuales a los de la institución (por ejemplo, piénsese en la sensibilización social creciente respecto del maltrato intrafamiliar) mientras que, paralelamente, se opera una reducción de ese mismo control social ejercido sobre múltiples dimensiones de la realidad familiar tradicionalmente sujetos a modelos normativos fuertemente arraigados ${ }^{2}$. En el seno de las familias se han creado espacios de libertad individual en la conformación de los

\footnotetext{
${ }^{\text {I }}$ Henderson, T.L., Moran, P. B., «Grandparent Visitation Rights. Testing the Parameters of Parental Rights» en Journal of Family Issues, 22, 200I, pág. 6I9.

${ }^{2}$ Meil Landwerlin G. «La figura del abuelo en las familias españolas en la actualidad», en Portularia, 3, 2003, págs. 33-47.
} 
proyectos de vida. La familia se ha democratizado como institución. Por otro lado, ya no hay una familia modelo, sino muchos modelos de familias posibles y legítimas.

Pero la profundidad e importancia de estos cambios no implica que la familia haya dejado de ser una realidad muy presente e importante en la vida cotidiana de los individuos y en la retórica política. De hecho, como bien apunta Lluis Flaquer, la sociedad española es fuertemente familiarista y otorga a la institución una función destacada en la cohesión social cubriendo además las carencias y deficiencias de un Estado que se proclama a sí mismo como de bienestar ${ }^{3}$. Un modelo que se encuentra hoy en día inmerso en una gran crisis económica pero también de identidad política En el discurso político y social dominante se presenta a familia como la célula básica de la sociedad, proveedora de todo tipo de cuidado y ayuda entre sus miembros y en el seno de la cual se encarna la solidaridad intergeneracional. Y es precisamente en virtud de ese importante papel que la familia juega que el Estado debe protegerla y apoyarla. De cualquier forma, como se pregunta Janet Finch, ¿qué significan en realidad estas concepciones de la familia?, ¿reflejan lo que la familia debería ser o lo que en realidad es? En alguna medida ¿no se podrían estar justificando recortes del acceso a servicios y ayudas que provengan del Estado haciendo patente el carácter superior de la ayuda que tiene su origen en la familia?4 Los diferentes miembros de la familia se prestan apoyo material y no material cuando se necesita, un apoyo que, como es bien sabido, no excluye el conflicto 5 . En este contexto, Flaquer concluye, con precisión casi diríamos que poética, que la familia supone en sociedades como la española un refugio contra la crisis y un dique contra el infortunio ${ }^{6}$.

Este cambio social de la estructura familiar operado en los últimos tiempos ha colocado también a los abuelos y abuelas en una nueva posición en la familia7. Los abuelos han dejado de ser, en líneas generales, una figura distante, de respeto casi reverencial (sobre todo el abuelo paterno). Podíamos decir que han bajado del pedestal a la vez que se han implicado de forma mucho más directa en las relaciones familiares con sus nietos y nietas. Autoras como Maria José Osuna datan este estrechamiento de las relaciones abuelos-nietos a partir de los años 80 del pasado siglo. Las principales causas del fenómeno serían el incremento en la expectativa de vida, el aumento de las familias multigeneracionales y los cambios generacionales que hacen que abuelos y abuelas presentes características muy diferentes de los abuelos de las generaciones anteriores ${ }^{8}$. Esas nuevas características de la abuelidad -si se me permite el neologismo- se encuentran directamente conectadas con el proceso más amplio de democratización familiar experimentado en países como España en las últimas décadas.

\footnotetext{
${ }^{3}$ Flaquer Villardebó, LL. El destino de la familia, Barcelona, Ariel, I998.

${ }^{4}$ FinCH, J., Family obligations and social change, Cambridge, Polity Press \& B. Blackwell, I989, pág. 237.

${ }^{5}$ BAZO, M.T., «Relaciones familiares y solidaridad intergeneracional en las nuevas sociedades envejecidas», en Panorama Social, I5, 20I2, pág. I30.

${ }^{6}$ Flaquer Villardebó, El destino de la familia, cit. pág. I3I.

${ }^{7}$ En concreto, Jerónimo González y Raquel de la Fuente realizan una certera enumeración de los cambios estructurales y culturales cruciales en la familia a los que han asistido las generaciones actuales de abuelos: el aumento de la esperanza y la calidad de vida, el rechazo al envejecimiento, la posibilidad de jubilarse anticipadamente, la tardía emancipación de los hijos, el descenso de la natalidad y la diversidad de comportamientos y costumbres familiares. DE LA FuenTE, R., GonZÁlEZ, J., «Visibilidad y reconocimiento de la generación de los mayores. La importancia de los abuelos en la vida familiar», en Panorama Social, I5, 20I2, pág. I59.

${ }^{8}$ OsunA, M.J., «Relaciones familiares en la vejez: vínculos de los abuelos y de las abuelas con sus nietos y nietas en la infancia» en Revista Multidisciplinar de Gerontología, ı6, 2006, pág. I7.
} 
A la vez que iba variando el significado de la maternidad y paternidad ${ }^{9}$ introduciéndose cada vez con más fuerza conceptos consideraciones de desarrollo personal a la hora de tener descendientes, también el rol del abuelo se ha ido modificando en su contenido. Los nietos y nietas -quizás de una forma mucho más marcada que los hijos e hijas- suponen de forma primordial una fuente de satisfacción personal para sus abuelos que además obtienen las alegrías y satisfacciones de esa especie de parentalidad tardía pero aligerada de las cargas y responsabilidades inherentes a la misma. Como concluye María Teresa Bazo, muchos de los roles que ejercen las personas mayores en el seno de la familia pueden tener un carácter instrumental (ayudar a los hijos a cuidar a los nietos y nietas, por ejemplo $)^{\text {IO }}$ pero quizás los más importantes son los que tienen un carácter expresivo ${ }^{\text {II }}$. No obstante, el rol de los abuelos y abuelas es más relevante en nuestras sociedades de lo que a veces se piensa y por ello no deja de sorprender la más bien escasa atención que se ha prestado a las relaciones abuelos/nietos por parte de la sociología de la familia ${ }^{22}$.

El sociólogo Gerardo Meil apunta además el papel que juegan los nietos y nietas como mediadores sociales entre las distintas generaciones. Lo habitual es que estas generaciones -sobre todo debido al aumento del nivel adquisitivo y a la extensión de las pensiones- mantengan una independencia residencial. De hecho la convivencia de los nietos y abuelos en un mismo hogar, cuando tiene lugar, se da con mayor frecuencia en la juventud que en la infancia puesto que los hogares de tres generaciones ya no son predominantemente familias troncales sino familias nucleares reagrupadas forzadas a ello por determinadas circunstancias, esencialmente la necesidad de provisión de cuidado hacia las personas mayores ${ }^{\mathrm{I3}}$. Aunque no se conviva en el mismo hogar, ello no implica que no se mantengan contactos con nietos y nietas que suelen ser frecuentes e intensos favoreciendo también un estrechamiento de las relaciones con los progenitores de los nietos, los hijos e hijas de los abuelos. En este sentido, la variable de la proximidad demográfica es esencial para propiciar el contacto entre generaciones.

Una dimensión importante a tener en cuenta para comprender esa mayor afinidad, al menos en el caso de nietos y nietas adolescentes, es la relativa similitud que comportan la juventud y la vejez: ambos grupos de edad son adyacentes al grupo dominante y ninguno de ellos tiene poder suficiente para tomar decisiones. A ambos grupos se les recuerda que no son productivos y se consideran inmersos en una sociedad que no les valora por ello.

\footnotetext{
9 El sociólogo Lluis Flaquer explica como el valor que los padres dan a sus hijos ha pasado de ser instrumental a expresivo. Aun a riesgo de simplificar demasiado, mientras en las sociedades tradicionales el nacimiento de los hijos estaba supeditado a intereses de orden superior en la actual su presencia viene justificada principalmente por el placer o la satisfacción que producen. FlaQUer Villardebó, El destino de la familia, cit. pág. IO०.

Io BAzo, M.T., «Aportaciones de las personas mayores a la sociedad. Análisis sociológico», en Revista Española de Investigaciones Sociológicas REIS, 73, 1996, pág. 210.

${ }^{\text {II }}$ En este sentido resultan reveladores algunos de los resultados obtenidos por un estudio acerca de la relación entre abuelos y nietos llevado a cabo por María José Osuna entre una muestra de abuelos y abuelas de la provincia de Barcelona. En las conclusiones de este trabajo se destaca el carácter birideccional de este tipo de relación familiar, como los abuelos dan a sus nietos afecto, cuidado, amor, experiencias de vida, amistad, comprensión, tiempo, etc $\cdots$ y éstos reciben cariño, compañía, vitalidad, diversión, comodidad, etc. Se observan diferencias relacionadas con el género: las abuelas enfatizan y valoran más la obtención de compañía (50\%) y vitalidad (37,5\%), mientras que los abuelos destacan la satisfacción $(28,5 \%)$ y la diversión (2I,43\%) que las relaciones con sus nietos y nietas les proporcionan. OsunA, M.J., «Relaciones familiares en la vejez: vínculos de los abuelos y de las abuelas con sus nietos y nietas en la infancia», cit., pág. I9.

${ }^{\text {I2 }}$ Meil Landwerlin, « La figura del abuelo en las familias españolas en la actualidad», cit. pág.34. OsunA, M.J., «Relaciones familiares en la vejez: vínculos de los abuelos y de las abuelas con sus nietos y nietas en la infancia», cit. pág.I7.

I3 MeIl Landwerlin, « La figura del abuelo en las familias españolas en la actualidad», cit. pág.37.
} 
De cualquier manera, la delimitación del significado social de ser abuelo o abuela no resulta una tarea sencilla porque existen muchas facetas superpuestas: es un símbolo, un rol social, una experiencia emocional, una interacción con el nieto o nieta que está inserto en un proceso grupal con el conjunto de la familia ${ }^{\mathrm{I}}$. Los abuelos, como ocurre con las personas mayores como colectivo, son un grupo heterogéneo cuyas actitudes y entendimiento de sus roles está determinado por variables diversas como la edad, el género, la clase social, la cultura, la frecuencia del contacto y la proximidad residencial en relación con los nietos. Sin embargo, como también ocurre también al referirnos al conjunto de las personas mayores, esta heterogeneidad no suele tenerse demasiado en cuenta. Además no hay que olvidar que aunque el rol de abuelo o abuela es muy importante para un número importante de las personas mayores, como es lógico, no todas las personas mayores tienen nietos o nietas ${ }^{15}$.

El rol de los abuelos en el seno de la familia ha sido comúnmente denominado como un rol sin rol, ya que no estaría gobernado por los derechos y obligaciones que tienen aparejados el rol de padre o madre. En el contexto de los apoyos familiares los abuelos (y, sobre todo, las abuelas) ejercen una labor de cuidado y de atención a sus nietos y nietas muy activa $^{16}$. Tradicionalmente los abuelos han sido cuidadores secundarios de sus nietos cuando los padres tenían que trabajar en momentos puntuales del año (cosechas, siembras, matanzas). En la actualidad este rol se mantiene e incluso se ha hecho más activo. Incluso en determinadas situaciones -como por ejemplo un divorcio, el ingreso en prisión de los progenitores, un contexto familiar de abuso de drogas o alcohol, el embarazo de una hija adolescente o una situación de malos tratos- los abuelos están asumiendo el cuidado de sus nietos como cuidadores principales. Esta labor de cuidado es especialmente relevante en supuestos de familias monoparentales, en casos de madres adolescentes o cuando madre y padre trabajan durante la mayor parte del día y de forma continuada ${ }^{\mathrm{T}}$. Pero como demuestran los datos disponibles, es frecuente que el nido vacío de los abuelos «se llene durante algunas horas todos los días para asumir el cuidado de los nietos» ${ }^{18}$.Y ello, en sistemas como el español en el que los servicios públicos y otros mecanismos para

${ }^{\text {I4 }}$ Pinazo Hernandis, S., «Significado social del rol de abuelo» en Revista Multidisciplinar de Gerontología, 9, I999, pág. I69.

${ }^{15}$ Ese apelativo de abuelos o abuelas se suele oír con cierta frecuencia para referirse a cualquier persona mayor. Al hilo de esta cuestión, Vicençs Navarro cuenta como su padre, respondía a sus 94 años con gran dignidad a las personas que le llamaban abuelo que ni era su abuelo ni deseaba serlo en la convicción de que si no se llama a las personas que no lo son esposos, tíos, hermanos ni ningún otro apelativo de parentesco, no tiene por qué llamarse a las personas mayores abuelos tampoco. Lo cierto es que la heterogeneidad del colectivo de las personas mayores, y dentro de éste, de los abuelos y abuelas no suele ser contemplada lo que, en mi opinión, resulta una sutil y velada manifestación de edadismo social. NAVARRo V, El subdesarrollo social de España: Causas y consecuencias, Barcelona, Anagrama, pág. I05.

${ }^{16}$ Según la segunda oleada de la encuesta la Encuesta de Salud, Envejecimiento y Jubilación en Europa (The Survey of Health, Ageing and Retirement in Europe, SHARE) en la que han participado participaron II países euroeos y referidos a 2006, entre el 23\% (Dinamarca) y el 70\% (Italia) de los abuelos con nietos menores de io años cuidan de ellos todos los días o todas las semanas. En España, un $55 \%$ de los abuelos cuidan de sus nietos regularmente y el 30\% declara hacerlo diariamente Son más las abuelas que cuidan a sus nietos diariamente (6I\%) que los abuelos (54\%). Con una edad media de 65 años los abuelos y abuelas que cuidan diariamente a sus nietos registran una edad media cuatro años menor que el conjunto de los abuelos. GARCía-MorÁn, E., KuenN, Z., «Relaciones entre generaciones y mercado de trabajo. La importancia de los abuelos en la participación laboral de las madres», en Panorama Social, I5, 20I2, págs.. 83 y 86.

${ }^{17}$ Buz Delgado, J., Bueno MartínEZ, B, «Las relaciones intergeneracionales», en Portal Mayores. Lecciones de Gerontología, 66, 2006, pág. 9.( disponible en

http://www.imsersomayores.csic.es/documentos/documentos/buz-relaciones-oI.pdf

fecha de consulta: 2I.I2.20I2)

${ }^{\text {I8 }}$ De la Fuente, R., GonzÁlez, J., «Visibilidad y reconocimiento de la generación de los mayores. La importancia de los abuelos en la vida familiar», cit. pág. I62. 
conciliación de la vida familiar y laboral están escasamente desarrollados, tiene una gran importancia de cara a la empleabilidad de las mujeres ${ }^{\mathrm{I}}$.

En el ejercicio de ese papel de cuidadores de los nietos se observan, además, importantes transformaciones relacionadas con la variable del género. Las abuelas, en sus relaciones familiares asumen cada vez más los valores de la autorrealización, independencia y autonomía personal en sus tratos con sus nietas y nietos y con la familia en general. En este nuevo escenario social el hecho de que la vejez se haya visto prolongada se convierte en una posibilidad real de superar carencias en la experiencia en función del género de hombres y mujeres mediante el desempeño de su papel de abuelos en un plano hipotético simétrico de funciones compartidas ${ }^{2 \circ}$. Abuelas y abuelos actuales desempeñan sus roles de género tradicionales -las abuelas un papel afectivo y de cuidado y los abuelos un papel instrumental vinculado a su experiencia laboral- pero, al lado de esos cometidos, los hombres que son abuelos asumen tareas de cuidado directo de sus nietos -tareas que probablemente no habían asumido con sus propios hijos e hijas- y las mujeres que son abuelas rechazan en parte las funciones clásicas del cuidado insistiendo en la importancia de un espacio propio y de la autonomía personal. Las mujeres siguen ejerciendo mayoritariamente esas funciones de cuidado (organizando, coordinando las tareas y a menudo diciendo a sus esposos lo que tienen que hacer) pero cada vez lo hacen más conjuntamente con los varones, sobre todo cuando aún vive la pareja puesto que la ayuda de los abuelos cuando están solos disminuye considerablemente. En cualquier caso, como muy acertadamente concluye Constanza Tobío, no hay que perder de vista que la primera generación de mujeres activas está encontrando ayuda en la última generación de amas de casa, sus propias madres, que están dispuestas y con ganas de ayudar para que sus hijas sean mujeres trabajadoras. Más que reciprocidad entre abuelas y madres hay un fenómeno de solidaridad puesto que las abuelas presumiblemente están aportando más de lo que van a recibir al haber cuidado a sus hijos y ahora cuidar a sus nietos ${ }^{2 \mathrm{I}}$.

Este cuidado que los abuelos (y, sobre todo, las abuelas) ejercen en relación con sus nietos y nietas tiene muchos aspectos positivos pero también puede presentar matices negativos al considerarse matizado, en determinados supuestos, por el concepto de obligación. Y esa obligación puede asumirse con mejor o peor grado y tener efectos positivos pero también negativos dependiendo de las circunstancias personales y la salud de las personas mayores. Estos efectos negativos, en circunstancias extremas, pueden llegar a fenómenos como el conceptualizado como síndrome de la abuela esclava ${ }^{22}$.

${ }^{19}$ Así, como señalaban recientemente Eva García- Morán y Zoe Kuehn a partir del análisis de los datos españoles de la encuesta SHARE, tener cerca a los abuelos y disponer de la posibilidad de que ellos cuiden de ellos de forma gratuita permite que más madres puedan trabajar. Pero dado que del análisis de esos datos se deduce que, entre quienes usan ese servicio de cuidado de niños por los abuelos, la mayoría de madres viven a menos de cinco kilómetros del domicilio de los abuelos, la necesidad de estar cerca de la casa de los abuelos implica restricciones geográficas sobre el mercado laboral de las madres que afectan negativamente a su salario. GarcíA-MorÁn, E., KueHn, Z., «Relaciones entre generaciones y mercado de trabajo. La importancia de los abuelos en la participación laboral de las madres», cit. pág.90.

${ }^{20}$ RAdl Philipp, R ., «Transformaciones en el comportamiento en función del género en la vejez: el caso de las relaciones familiares entre abuelas, abuelos y nietas y nietos», en Papers: revista de sociología 70, 2003, pág. II8.

${ }^{21}$ Toвío, C., «Redes familiares, género y política social en España y Francia», en Política y sociedad, 2, 2008, pág IOI.

${ }^{22}$ Según descripción de Guijarro Morales, se trataría de un problema sanitario y social muy frecuente y grave en mujeres adultas e incluso potencialmente mortal a veces por suicidio. El origen de una abuela esclava sería una mujer adulta con responsabilidades directas de ama de casa, voluntariamente asumidas con agrado que, por razones educacionales y psicológicas tiene un sentido extraordinario del orden y la responsabilidad. Llega un momento en que las capacidades y la voluntad de la abuela no son suficientes para cumplir las tareas que desde hace años está desempeñando (de cuidadoso de los nietos y de atención a todos los miembros de la familia - sanos y enfermos, niños, jóvenes y viejos - en realidad). Pero no renuncia a ellas y se produce un desequilibrio. La abuela acude reiteradamente a los médicos y servicios de urgencia, contando sus achaques pero sin desvelar claramente el estrés al que se encuentra sometida. Para Flórez Lozano se trata de un cuadro 
Podemos concluir que, en el contexto social y familiar actual, incluso de manera más marcada por la crisis económica, los abuelos prestan una serie de servicios muy variados a las familias, a sus hijos y a sus nietos: unos servicios con un valor específico y difícilmente sustituible ${ }^{23}$. Entre ellos, en muchas ocasiones, el apoyo y cariño hacia sus nietos que se basa en relaciones personales estrechas y profundas y que, salvo excepciones, resulta beneficioso para el desarrollo pleno y armónico de los menores. Precisamente a los concretos términos en los que el ordenamiento español reconoce el derecho y su ejercicio al mantenimiento de las relaciones personales entre abuelos y nietos dedicamos el siguiente apartado.

\section{El régimen legal del derecho a las relaciones personales entre abuelos y nietos en el ordenamiento jurídico español}

La regulación esencial de las relaciones familiares entre los abuelos y los nietos en su configuración actual parte de la Ley 42/2003 de 2I de noviembre que reforma algunos de los artículos del CC y de la LEC. A pesar de que ese derecho se introduce por primera vez de forma general en la Ley II/I98I, de I3 de mayo, de modificación del CC en materia de filiación, patria potestad y régimen económico del matrimonio (BOE II9, I9 de mayo de I98I) poniendo un importante límite al hasta entonces poder omnímodo de los padres reconociendo un derecho de relación directa de los menores con otros parientes $y$ allegados, a través de la reforma del 2003 se vino a operar un reforzamiento de las relaciones entre abuelos y nietos al incluir expresamente en el art. r6o CC la mención a los abuelos.

Hay que puntualizar que la locución derecho de visitas, como a veces se denomina, a pesar de resultar breve y cómoda, permitiendo identificar claramente el concepto al que alude, resulta imprecisa puesto que parece referirse solo a parte del contenido del derecho al que hace referencia. Este derecho abarca en su concepción actual un amplio haz de facultades que implica el trato el trato personal entre los sujetos afectados, el derecho del abuelo a recibir en su domicilio y albergar al menor siguiendo cierto calendario, y el derecho a mantener correspondencia de todo tipo ${ }^{24}$. Por eso mismo la terminología más correcta es la que acoge el propio legislador al referirse al derecho a las relaciones personales.

En este apartado nos ocuparemos, al hilo de los cambios sociales que ya hemos revisado con anterioridad, del análisis de ese régimen jurídico del derecho a las relaciones personales de entre los abuelos y abuelas y sus nietos y nietas en sus elementos esenciales de carácter sustancial.

clínico de difícil diagnóstico con multiplicidad de síntomas crónicos de enfermedades comunes, pero que no responden a tratamientos convencionales y que provoca un sufrimiento crónico con un notable deterioro de la calidad de vida. Guijarro Morales, A., El síndrome de la abuela esclava: pandemia del siglo XXI, 2001, Granada, Grupo editorial Universitario. FLóREZ LOZANO, J.A «El síndrome del cuidador». en Jano Medicina $y$ Humanidades, 558, 2004, págs. 46.

${ }^{23}$ De la Fuente, R., González, J., «Visibilidad y reconocimiento de la generación de los mayores. La importancia de los abuelos en la vida familiar»,cit.,pág.I63.

${ }^{24}$ Berrocal LanZarot, A.I, «Reflexiones sobre las relaciones familiares entre abuelos y nietos tras la nueva Ley 42/2003, de 2I de noviembre» en Anuario de Derechos Humanos.,vol. 6,. 2005, págs. 46-47; ColAS EsCANDÓN, A.M., Relaciones familiares de los nietos con sus abuelos: derecho de visita, estancia, comunicación $y$ atribución de la guarda y custodia, Cizur Menor (Navarra), Thompson Aranzadi, 2005, págs. 39 y ss; GARCÍA CANTERo, G., Las relaciones familiares entre nietos y abuelos según la Ley de 21 de noviembre de 2003, Madrid, Cuadernos Civitas, 2003, págs.27 y ss. 


\section{III.I. Finalidad de la ley}

Dado nuestro acercamiento sociojurídico antes que dogmático al objeto de análisis, conviene que previamente al abordaje de su contenido nos detengamos en analizar en qué situaciones y contextos familiares se ejerce este derecho a las relaciones familiares entre abuelos y nietos.

Al respecto, Colás Escandón, apunta hacia una serie de supuestos, más o menos presentes en la sociedad española actual, que justificarían este derecho tanto de los nietos como de los abuelos ${ }^{25}$. Habitualmente se trata de situaciones de ruptura de la pareja en la que la guarda y custodia del menor queda confiada a uno de los progenitores y en la que la mala relación previa o la falta de acuerdo puede dificultar el mantenimiento de las relaciones con los abuelos de la rama familiar del progenitor no custodio. Pero también podemos pensar en situaciones de fallecimiento de uno de los cónyuges en los que el superviviente no garantiza el contacto entre el menor y sus abuelos por parte del progenitor fallecido. O simplemente casos en los que la pareja de progenitores no está en crisis pero mantienen malas relaciones con los abuelos impidiendo el contacto de los hijos con ellos a pesar de que los menores deseen seguir manteniendo esas relaciones. También cabe pensar en la adopción del menor por otra familia existiendo una fuerte vinculación previa de éste con sus abuelos biológicos. En definitiva, como sintetiza Beatriz Verdera, la mayoría de las sentencias tienen su base en situaciones de falta de armonía entre los progenitores y los abuelos tras una crisis matrimonial o en el fallecimiento de uno de los progenitores del o de la menor ${ }^{26}$. No obstante otras autoras, apuntan que frente a la fijación de un régimen de comunicación y estancia fijado ya sea de manera convencional ${ }^{27}$ o contenciosa en el contexto de un proceso de separación o divorcio que resulta poco habitual desde el punto de vista social, la vertiente sustantiva y procesal más frecuente sería la de la reclamación de los abuelos frente a los dos titulares de la patria potestad ${ }^{28}$ en caso de conflicto personal entre

${ }^{25}$ Colas Escandón, A.M., Relaciones familiares de los nietos con sus abuelos: derecho de visita, estancia, comunicación y atribución de la guarda Y custodia, cit. págs. I7 y ss.

${ }^{26}$ Verdera IZquierdo, B., «Situación actual del derecho de visita a las abuelos», Comunicación, I Congrés estatal sobre la defesa dels menors a las crises de parella, 2008, págs. I-I2 (disponible en http://ibdigital.uib.es/greenstone/collect/portal_social/archives/D_I2.dir/D_I2.pdf; fecha de consulta: 7-I220I2).

${ }^{27}$ Berrocal Lanzarot plantea que esta posibilidad de fijación del régimen de relaciones personales entre abuelos y nietos por vía de convenio es realmente excepcional en la práctica puesto que los cónyuges buscan acuerdos sobre mínimos en cuestiones que les afectan conjunta y recíprocamente, y en estos mínimos no suele estar la decisión sobre el régimen de visitas de los abuelos tanto maternos como paternos, en la que, además, éstos no participan. La frágil línea sobre la que se sustentan los acuerdos en situaciones de crisis, exige evitar, por pequeño que sea, cualquier motivo que conlleve discrepancia. BERROCAL LANZAROT, A.I, «Reflexiones sobre las relaciones familiares entre abuelos y nietos tras la nueva Ley 42/2003, de 2I de noviembre», cit. pág. 72.

${ }^{28}$ Aunque nosotros seguiremos refiriéndonos esencialmente a la patria potestad que es el que tradicionalmente se ha utilizado en el ordenamiento jurídico español, como recuerda Villagrasa Alcaide, se evidencia una evolución terminológica desde la patria potestad hacia la potestad parental o potestad de los progenitores, incluso en la legislación, vinculado con una cuestión de género y también con una definición del contenido de las facultades, deberes y funciones inherentes. Se ha ido produciendo una transformación de sus tradicionales perfiles delimitados por la autoridad absoluta del padre y marido, constituyéndose en una institución definida por el concepto de función, presidida por el principio de interés superior del menor, con una intervención garantista cada vez mayor de los poderes públicos y una participación directa del propio menor cuando sea posible por su grado de discernimiento. En este sentido, estas transformaciones y matices que ha ido adquiriendo la institución deben ser tenidos en cuenta cuando hablamos de patria potestad. VILLAGRASA AlCAide, C., «La custodia compartida en España y en Cataluña: Entre deseos y realidades», en, PiConTÓ, Novales, T., (ed.), La custodia compartida a debate, Cuadernos Bartolomé de las Casas, 56, Madrid, Dykinson, pág. 8I. 
unos y otros y la reclamación de los abuelos frente al titular único de la patria potestad en caso de fallecimiento del descendiente de los demandantes ${ }^{29}$.

En concreto, la reforma en la materia introducida en 2003 tiene un doble objetivo: de un lado, singularizar de forma explícita y reforzada el régimen de relaciones entre los abuelos y los nietos; de otro lado, atribuir una función relevante a los abuelos en caso de dejación de los padres de las obligaciones derivadas de la patria potestad ${ }^{30}$. La finalidad última de este derecho a las relaciones personales no es otra que la de favorecer el desarrollo integral del nieto merced al cariño, apoyo y consejos que sus abuelos puedan ofrecerle $^{3 \mathrm{I}}$. Y en el caso específico de ruptura o crisis familiar se trataría de no gravar al nieto o nieta con las secuelas de las separaciones y conflictos familiares y de no amputar una relación con personas que le son cercanas humana y afectivamente. Como recuerda Corvo López, la misma Exposición de Motivos de la Ley 42/2003, tras resaltar el papel de cohesión y de transmisión de valores que desempeñan los abuelos en la familia insiste en el rol que éstos pueden asumir para ayudar al niño o la niña a racionalizar las situaciones de conflicto familiar favoreciendo su estabilidad y desarrollo ${ }^{32}$.

III.2. Alcance y contenido esencial del derecho a las relaciones personales entre abuelos y nietos

Muy sintéticamente podemos señalar que el contenido de la Ley 42/2003 se limita a introducir reformas parciales en algunos preceptos del CC y de la LEC, conservando sustancialmente su contenido aunque completándolo o adicionando algún nuevo elemento relacionado con la cuestión objeto de la norma ${ }^{33}$. La reforma más importante y de mayor resonancia jurídica y social se ha producido en los párrafos $2^{-}$y $3^{\circ}$ del art. ${ }^{\circ} 60 \mathrm{CC}$ a través de los cuales se reconoce el derecho a las relaciones personales entre los hijos y los abuelos $^{34}$. En el tenor literal de la norma no se habla de nietos sino de hijos porque se trata de una referencia genérica al incluirse en el mismo párrafo también la mención a otros parientes y allegados. La redacción puede resultar algo confusa en este punto, sobre todo

${ }^{29}$ Guilarte Martín-CAlero, C., «El derecho de los nietos a mantener relaciones personales con sus abuelos (A propósito de la sentencia del Tribunal supremo de 20 de octubre de 20II)», en Revista de Derecho de Familia, 56, 20I2, pág. 48.

${ }^{30}$ Guilarte Martín-Calero, C., «El derecho de los nietos a mantener relaciones personales con sus abuelos (A propósito de la sentencia del Tribunal supremo de 20 de octubre de 20II)», cit. págs. 47-48.

${ }^{31}$ En este sentido, el Tribunal Supremo ya venía insistiendo, desde antes de la reforma de 2003, en el beneficio que las relaciones con los abuelos reportan con el menor en cuanto lo insertan en el entorno familiar completo, ayudando a forjar su personalidad, su formación e integración social (SSTS de i7 de septiembre de I996, de in de junio de i998 y de 23 de noviembre de I999).

${ }^{32}$ Corvo LópeZ, F., «A propósito de la nueva regulación de los niños con sus abuelos en Francia y en España», en Alonso Pérez, M., Martínez Gallego, E.M., Reguero Celada J. (coords.), Protección Jurídica de los mayores, Madrid. La Ley, 2004, pág. 353.

${ }^{33}$ Resulta de innegable interés el análisis de la tramitación parlamentaria de la Ley que hace Berrocal Lanzarot. La mencionada autora destaca como en su análisis como la tramitación se caracterizó por su su brevedad y por reflejar fielmente, además de los posicionamientos enfrentados de los diversos grupos parlamentarios - hubo 42 enmiendas en el Congreso y i6 en el Senado hasta alcanzar el texto definitivo - la división de la doctrina donde, o bien se postula desde sus filas, la innecesariedad de la reforma y su carácter jurídicamente inadecuado; o bien, por el contrario, se destaca su indiscutible valor para consolidar una relaciones beneficiosas para el nieto menor de edad no emancipado o incapacitado. BERROCAL LANZAROT, «Reflexiones sobre las relaciones familiares entre abuelos y nietos tras la nueva Ley 42/2003, de 2I de noviembre», cit. págs. 22-37

34 El tenor literal del art. I60, en concreto de sus párrafos $2^{\circ}$ y $3^{\circ}$ señala: «No podrán impedirse sin justa causa las relaciones personales del hijo con sus abuelos y otros parientes y allegados. En caso de oposición, el juez, a petición del menor, abuelos, parientes o allegados, resolverá atendidas las circunstancias. Especialmente deberá asegurar que las medidas que se puedan fijar para favorecer las relaciones entre abuelos y nietos, no faculten la infracción de las resoluciones judiciales que restrinjan o suspendan las relaciones de los menores con alguno de sus progenitores». 
teniendo en cuenta que el párrafo siguiente se refiere al menor. A través de esta nueva redacción del precepto se singulariza y destaca la relación entre abuelos y nietos (aunque se haga referencia también a otros parientes y allegados) de acuerdo con la finalidad de la ley de impulsar y promocionar como criterios de política jurídica tales relaciones y procurando que el juez pueda favorecerlas con sus decisiones sobre la materia.

No obstante para Marta Carballo este reforzamiento de las relaciones entre abuelos y nietos operado por la norma resulta muy tímido y la expresa alusión por parte del párrafo segundo del art. I6o CC a abuelos parientes y allegados, donde antes se hablaba de parientes y allegados no entraña modificación sustancial alguna dado el indudable vínculo de parentesco existente entre abuelos y nietos ${ }^{35}$. Sin embargo, para García Cantero, la ley ha expresado su voluntad no solo de que se acepten sino de que se favorezcan tales relaciones por decisión judicial lo que ciertamente no se afirma respecto de otras relaciones del menor con parientes y allegados ${ }^{36}$. La nueva redacción del artículo incluye también un inciso final en el que se advierte a los jueces para que, por la vía del derecho a las relaciones personales de los abuelos con sus nietos no se burlen otras medidas preventivas dictadas para evitar situaciones de violencia de género (esencialmente el alejamiento y la prohibición de comunicarse respecto de los hijos o incluso de la pareja) lo que, como es evidente, resultaría una forma de abuso o de uso fraudulento de ese derecho.

Respecto al acogimiento, la nueva redacción otorgada al art. I6 I CC $^{37}$ supone la inclusión, junto a los progenitores, de los abuelos y los demás parientes entre los legitimados para solicitar el derecho a las relaciones personales respecto del menor acogido. De todas maneras, como recuerda García Cantero, hay que tener en cuenta el carácter polimórfico de la institución del acogimiento familiar, por lo que el juez deberá siempre tener en cuenta a la hora de aplicar este precepto la clase y finalidad del acogimiento de que se $\operatorname{trata}^{38}$.

En otro orden de cosas, las modificaciones introducidas en los arts. 90 y 94 CC tratan de recoger y poner en valor la posible influencia benéfica de los abuelos y abuelas en los conflictos o crisis del matrimonio de los progenitores. Se distinguen dos situaciones diferentes: la existencia de un convenio regulador, o bien que no exista acuerdo y ese derecho de comunicación y visita lo tenga que determinar el juez ${ }^{39}$.

${ }^{35}$ Carballo Fidalgo, M., «El derecho de visita de los abuelos y la atribución de la guarda de sus nietos tras la ley 42/2003, de 2I de noviembre. Aspectos sustantivos y procesales», en Revista de Derecho de familia, 30, 2006, pág. 48.

${ }^{36}$ García CANTERo, Las relaciones familiares entre nietos y abuelos según la Ley de 21 de noviembre de 2003, cit. pág.II7.

37 El mencionado art. I6ıг CC, en su redacción actual señala: «Tratándose del menor acogido, el derecho que a sus padres, abuelos y demás parientes corresponde para visitarle y relacionarse con él, podrá ser regulado o suspendido por el juez, atendidas las circunstancias y el interés del menor».

${ }^{38}$ En el acogimiento simple (art. I73 bis I ${ }^{-}$CC) esta norma tiene pleno sentido por preverse la reinserción del menor en su propia familia. Mientras que en el acogimiento permanente (art. I73 bis $2^{-}$CC) el juez valorará las causas que lo originaron, las cuales pueden incluso aconsejar un alejamiento, al menos mientras subsistan entre abuelos y nietos. En el acogimiento preadoptivo (art. I73 bis $3^{-} \mathrm{CC}$ ) será prudente reducir y suspender tales contactos que en cualquier caso desaparecerán con la adopción. Y, por último, en el caso del acogimiento decidido por el juez sin consentimiento o en contra de la voluntad de los padres (art. I73.3 CC) el derecho para visitarle o relacionarse con ellos puede variar a tenor de la actitud que, frente a la medida judicial, adopten sucesivamente los progenitores con los menores y éstos con aquéllos. GARCÍA CANTERO, Las relaciones familiares entre nietos $Y$ abuelos según la Ley de 21 de noviembre de 2003, cit. pág.II9.

39 En caso de existir convenio, se introduce a través del art. 90 b CC, como posible contenido del mismo «Si se considera necesario, el régimen de visitas y comunicación de los nietos con sus abuelos, teniendo en cuenta, siempre, el interés de aquéllos». Lo que obliga también a intercalar en el antepenúltimo párrafo del mismo artículo esta mención a la audiencia previa de los abuelos: «Si las partes proponen un régimen de visitas y comunicación de los nietos con los abuelos, el juez podrá aprobarlo previa audiencia de los abuelos en la que éstos presten su consentimiento». En el caso de no existir acuerdo, el art 94 CC señala al respecto: «Igualmente 
Finalmente el art. I03 CC, referido a medidas provisionales en caso de nulidad, separación o divorcio, recoge la posibilidad de encomendar a los hijos a los abuelos, parientes $\mathrm{u}$ otras personas allegadas que así lo consintieren confiriéndoles funciones tutelares que se ejercerán bajo la autoridad del juez. Para Fátima Yáñez, el cambio en este punto no parece especialmente trascendente por cuanto en la práctica y sin necesidad de mención expresa de los abuelos, en supuestos excepcionales, se viene concediendo la custodia a aquéllos en preferencia a otros parientes. En este sentido, estamos de acuerdo con la mencionada autora en su opinión de que la mención que así lo consintieren, no parece aportar demasiado al espíritu de la norma, ya que «si la finalidad de la misma es la de dejar el cuidado de los hijos en manos de personas con las que éstos tengan especiales vínculos de afectividad, mal se va a conseguir esta finalidad si la custodia se atribuye a esas personas en contra de su voluntad» $»^{\circ}$.

Siguiendo a García Cantero, podemos señalar que la actual regulación del tema objeto de este artículo determina una diferenciación sobre el derecho a las relaciones personales entre abuelos y nietos basado en si ese derecho se otorga con motivo de un proceso de nulidad, separación o divorcio o si es otorgado por el juez sin esas connotaciones $^{4 \mathrm{I}}$. Este último supuesto puede considerarse como la modalidad general mientras que cuando el otorgamiento del derecho viene asociado a un proceso de crisis matrimonial podemos hablar de una modalidad especial o subespecie. Esta diferencia se traduce en una normativa propia (art. I60 CC para la modalidad general y arts. 90,94 y I03 para la modalidad especial).

Para que un juez, competente en un proceso de nulidad, separación o divorcio pueda atribuir un derecho de relaciones a los abuelos (o alguno de ellos) hacen falta más requisitos que en los casos de una solicitud de visitas normal $u$ ordinaria. En primer lugar se requiere la proposición de los cónyuges (de ambos) cuando no existe convenio regulador. En segundo lugar se exige audiencia de los abuelos, aunque no se aclara si tiene que darse audiencia a todos ellos o solo al beneficiario o beneficiarios del derecho. Y por último, en tercer lugar, se pide el consentimiento otorgado por los solicitantes en presencia judicial. Los demás requisitos serían comunes a la modalidad general del derecho de visitas debiendo tenerse en cuenta siempre el interés del menor así como las precauciones recogidas en el art. I6o CC in fine de cara a evitar que se burlen medidas de alejamiento y de prohibición de comunicación respecto de algunos de los progenitores por esta vía indirecta.

\section{III.3. Naturaleza del derecho}

Respecto a la naturaleza del derecho a las relaciones personales entre abuelos y nietos la doctrina presenta diversos planteamientos y matices. Para García Cantero se trata de un derecho de contenido puramente afectivo y carácter extra patrimonial que permite a su titular expresar sus sentimientos a otra persona, exigiendo la utilización de los medios necesarios para alcanzar tal fin. Se encuadraría sistemáticamente entre los derechos de la personalidad y aunque habitualmente su ejercicio puede quedar enmarcado por el derecho a la intimidad es más amplio que éste ${ }^{42}$. Sin embargo, para Colás Escandón estaríamos más

podrá determinar, previa audiencia de los padres y de los abuelos, que deberán prestar su consentimiento, el derecho de comunicación y visita de los nietos con los abuelos, conforme al artículo iGo de este Código, teniendo siempre presente el interés del menor».

$4^{\circ}$ YAÑEz Vivero, Ma ${ }^{a}$, «El derecho del menor a relacionarse con los abuelos en situaciones de ruptura familiar y desamparo», en Ravetllat Ballesté, I., Villagrasa AlCAide, C. (coords.), Los derechos de la infancia $Y$ de la adolescencia, Barcelona, Ariel, 2006, pág. I85.

${ }^{4 \mathrm{I}}$ García CANTERo, Las relaciones familiares entre nietos y abuelos según la Ley de 21 de noviembre de 2003, cit. pág.I54.

${ }^{42}$ García CANTERo, Las relaciones familiares entre nietos y abuelos según la Ley de 21 de noviembre de 2003, cit. pág.I54. 
bien ante un derecho personal incluido en el ámbito de los derechos familiares ya que ni abuelos ni nietos, hasta que se haya establecido una medida judicial o convencional para ello, tienen obligación alguna de mantener relaciones personales y este derecho no se encuentra incluido en el elenco de derechos recogidos en la Constitución Española ${ }^{43}$. Esta postura es mantenida también por autoras como Berrocal Lanzarot y Diaz-Alabart, para quien «si bien excede de ese marco en sentido estricto, puesto que se reconoce no solamente a parientes, sino a personas que mantienen una relación de especial intensidad con el menor o incapacitado que por sus características puede llegar a tacharse de pseudo familiar o cuasi familiar» ${ }^{4}$.

En cierto sentido, como explica García Cantero ${ }^{45}$, el derecho a las relaciones personales entre abuelos y nietos supone un límite al ejercicio de la patria potestad por los progenitores. En todo caso, la patria potestad no podrá ser considerada como un poder discrecional, puesto que se trata de una función a ejercer siempre en interés del hijo o hija. Al otorgarse ese derecho de relación personal a los abuelos -y en determinados casos a otros parientes y allegados- con independencia de la voluntad de los padres, parece evidente que la relación de los menores con los terceros no se contempla desde la perspectiva del progenitor, que debe soportarla y posibilitarla. De cualquier forma no hay que olvidar que en el régimen del derecho común la patria potestad es una función familiar que se desarrolla exclusivamente entre procreadores y procreados, sin intervención legal de los ascendientes de segundo o ulterior grado. Los abuelos que hipotéticamente se hicieran cargo de sus nietos serían guardadores de hecho salvo que se les otorgue la tutela de los menores en los términos legales establecidos pero en ningún caso se les podrán atribuir facultades de la patria potestad de los progenitores, bien porque ésta se extingue con su fallecimiento o porque la siguen manteniendo si no les ha sido arrebatada por decisión judicial $^{46}$.

Como señala Carballo Fidalgo, este derecho recogido en los párrafos segundo y tercero del art. I6o CC, pese a su formulación negativa, como límite de la autoridad paterna, ha sido mayoritariamente interpretado como un derecho propio y autónomo a las relaciones personales del hijo y sus parientes y allegados. Un derecho subjetivo vinculado al libre desarrollo de la personalidad del que uno y otro son titulares y que, por lo tanto, uno y otro pueden reclamar en justicia: tanto el menor o la menor para obtener la efectividad de

${ }^{43}$ Colas EsCANDÓn, Relaciones familiares de los nietos con sus abuelos: derecho de visita, estancia, comunicación $Y$ atribución de la guarda y custodia, cit. pág.30.

44 BERROCAL LANZAROT, «Reflexiones sobre las relaciones familiares entre abuelos y nietos tras la nueva Ley 42/2003, de 2I de noviembre», cit. pág. 68; DiAZ-ALABART, S., «El derecho de relación personal entre el menor y sus parientes y allegados (artículo I60.2 del Código Civil) en Revista de Derecho Privado, Mayo-Junio, 2003, pág.355.

45 GARCía CANTERo, Las relaciones familiares entre nietos y abuelos según la Ley de 21 de noviembre de 2003 , cit. págs.34 y 39.

${ }^{46}$ Habría que mencionar aquí la excepción que supone la regulación aragonesa. Como es bien conocido y ya se recogía en la Observancia segunda de los Fueros aragoneses (circa I428) de consuetudine regni non habemus patriam potestatem, esto es «por costumbre del reino no tenemos patria potestad». La autoridad familiar, la figura que la sustituye en el régimen civil aragonés, se configura como el poder adecuado, como el medio de cumplimiento del deber de crianza del menor. Y esa autoridad familiar, a diferencia de lo que ocurre en el derecho común, puede ser asumida por los abuelos según señala el art. 73 de la Ley I3/2006 de 27 de noviembre de Derecho de la persona (BOA I49 de 30 de diciembre de 2006). El sistema histórico aragonés supone en este sentido, como reconoce Berrocal Lanzarot de forma novedosa y única en España, una excepción al reconocer la asunción del ejercicio de la autoridad familiar a los abuelos en caso de fallecimiento de los padres y de que existiendo un padrastro o madrastra éste o ésta no asuman la autoridad familiar. Según el art. 73.2 de la Ley aragonesa de Derecho de la persona se da preferencia aquellos abuelos que tengan una mayor relación con el nieto y cuando los abuelos de una misma rama vivan separados se atribuye a aquél que más se ocupe del nieto y, en última instancia al de menor edad. PARRA LuCÁN, M.A., «Capacidad y estado de las personas», en DELGADO ECHEVERRÍA, J. (dir.), Manual de Derecho civil aragonés, Zaragoza, Justicia de Aragón, 2007, pág.I58. BerRoCAL LANZAROT, «Reflexiones sobre las relaciones familiares entre abuelos y nietos tras la nueva Ley 42/2003, de 2I de noviembre», cit. pág. I03. 
esa relación como los parientes y allegados (incluidos los abuelos) solicitando que no se impida su mantenimiento aunque se condicione al interés del menor o la menor como parte débil de la relación ${ }^{47}$. En definitiva, se trata de un derecho que tiene de titular por una parte a los nietos y por otra parte a los abuelos y que puede suponer una cierta injerencia en las funciones que la patria potestad encomienda a los padres.

\section{III.4. Contenido, ejercicio y límites del derecho}

Como ya apuntábamos más arriba bajo la denominación derecho a las relaciones personales entre abuelos y nietos se abarcan varias situaciones diferentes: la visita sin pernocta del nieto o la nieta en su propio domicilio o en el de los abuelos, la visita con pernocta del nieto en el domicilio de los abuelos, la visita sin pernocta en un lugar diferente (habitualmente un Punto de Encuentro Familiar) y/o la simple comunicación entre abuelos y nietos por cualquier vía ${ }^{48}$. Este derecho incluiría en su posible contenido tanto el derecho de visitas en sentido estricto como el de estancia y comunicación dependiendo de las circunstancias y de la fijación convencional o judicial del mismo. El carácter deliberadamente amplio de la expresión derecho a las relaciones personales, como apunta Marta Carballo, es un acierto ya que permite que, en cada caso se dote de un contenido sensible a las circunstancias concurrentes (lugar de residencia de los abuelos, estado de salud, horarios escolares de los menores y laborales de los abuelos y padres, grado de relación entre los abuelos, padres y nietos, etc $\cdots)^{49}$. El Tribunal Supremo ha reconocido que la relación personal de los abuelos con los nietos no puede limitarse «a un mero contacto durante un breve tiempo» (STS de 28 de junio de 2004) aunque tampoco debe equipararse al régimen que se establecería en favor del titular de la patria potestad en un procedimiento matrimonial o de guarda y custodia de hijos no matrimoniales que necesariamente será más amplio pues se pretende además de fomentar la corriente afectiva de hijos con progenitores facilitar el adecuado ejercicio de la función parental en los términos establecidos por el art. I54 $\mathrm{CC}^{50}$. Entre esos límites y atendiendo a las circunstancias concurrentes el contenido y extensión de el derecho varía considerablemente ${ }^{5 \mathrm{I}}$.

El ejercicio del derecho genera en los abuelos una serie de obligaciones que se resumen en la obligación de perseguir siempre el interés superior del nieto o nieta. En concreto existiría una obligación de recoger y entregar al menor en el lugar y momento establecidos por las partes o el juez. Pero también existe una obligación de cuidar al nieto mientras se desarrollan las visitas sin presencia de los progenitores entendiendo ese concepto de cuidar en un sentido comprensivo del deber de proporcionar sustento, de

${ }^{47}$ CARBAllo FIDALGo, «El derecho de visita de los abuelos y la atribución de la guarda de sus nietos tras la ley 42/2003, de 2I de noviembre. Aspectos sustantivos y procesales», cit., pág. 48.

${ }^{48}$ Colas EsCANDón, Relaciones familiares de los nietos con sus abuelos: derecho de visita, estancia, comunicación $Y$ atribución de la guarda y custodia, cit. pág. 97.

49 La STS de i2 de mayo de 20 II señala que al no establecer el art. I6o CC ni la extensión ni la intensidad de los periodos en los que el menor puede relacionarse con sus abuelos o allegados, la cuestión deberá ser decidida por el juez atendiendo a la situación personal del menor y de la persona con quien desea relacionarse; a las conclusiones de los diferentes informes psicológicos que se hayan pedido; a la intensidad de las relaciones anteriores, a la no invasión de las relaciones del menor con el titular de la patria potestad y ejerciente de la guarda y custodia y, en general, todas aquellas que sean convenientes pare el menor. GUILARTE MARTínCALERO,«El derecho de los nietos a mantener relaciones personales con sus abuelos (A propósito de la sentencia del Tribunal supremo de 20 de octubre de 20II)»,cit., pág. ${ }_{5}^{6}$.

$5^{\circ}$ GUilarte Martín-CAlero, «El derecho de los nietos a mantener relaciones personales con sus abuelos (A propósito de la sentencia del Tribunal supremo de 20 de octubre de 20II)»,cit. pág. 56.

${ }^{5}$ En la praxis jurisprudencial mientras algunas sentencias concretan el derecho de visitas de los abuelos como parte del contenido de ese derecho a las relaciones personales con sus nietos fijándolo en un corto periodo semanal o quinquenal ( 2 o 3 horas) mientras otras amplían enormemente tal régimen, otorgando a los abuelos el derecho de tener a sus nietos un fin de semana de cada mes y un número de días variable en periodos vacacionales. CARBAllo FidAlgo, «El derecho de visita de los abuelos y la atribución de la guarda de sus nietos tras la ley 42/2003, de 2I de noviembre. Aspectos sustantivos y procesales», cit., pág. 50. 
vigilar la salud física y psíquica y de ofrecer un trato cálido y afectuoso ${ }^{52}$. Lo que parece quedar excluido de ese derecho son las funciones educativas que corresponden a los padres a través del ejercicio de la patria potestad. Aunque en ese sentido es innegable que el ejercicio de ese derecho a la relación personal con los nietos coloca a los abuelos en una posición en la que pueden ejercer cierta influencia sobre los mismos (fijación de horarios, alimentación, horarios, exposición a la televisión) aunque sin determinar la educación de éstos.

En cuanto a la posible modificación del régimen de relaciones personales, como es lógico, éste puede ser de dos tipos: tanto para ampliarlo como para restringirlo. El régimen que se establezca judicialmente va a tener un carácter progresivo, lo cual significa que su desarrollo se encontrará sujeto al control del equipo técnico del juzgado, de tal forma que, según la evolución de la relación se promover la ampliación, reducción o mantenimiento del régimen previsto inicialmente atendiendo siempre a lo que resulte más beneficioso para el o la menor ${ }^{53}$. La modificación de las circunstancias objetivas iniciales que sirvieron para la inicial fijación del régimen facultará para abrir nuevamente el caso ${ }^{54}$.

En relación con la posibilidad de denegación o suspensión del régimen de relaciones personales entre abuelos y nietos. El art. I60 CC se limita a prescribir la imposibilidad de negar las relaciones personales entre abuelos y nietos salvo que concurra una justa causa. El legislador parte de una presunción iuris tantum de que las relaciones entre nietos y abuelos favorecen el interés de estos últimos ${ }^{55}$. Esta presunción, si pretende ser negada -habitualmente por los progenitores o los tutores del menor- deberá ser destruida probando la existencia de una justa causa por quien la haga valer ${ }^{56}$.

En términos generales, puede entenderse que existe una justa causa siempre que la relación del menor con los abuelos pueda perjudicar al niño o niña, o poner en peligro su salud, su seguridad, su formación o educación. En este sentido, existe cierto paralelismo entre estas justas causas y los motivos por los que, de acuerdo con el art. 94 CC, pueden

${ }^{2}$ COLAS ESCANDÓN, Relaciones familiares de los nietos con sus abuelos: derecho de visita, estancia, comunicación $Y$ atribución de la guarda y custodia, cit. pág. I07.

${ }^{53}$ Convo López, F., «A propósito de la nueva regulación de los niños con sus abuelos en Francia y en España», cit. pág. 368.

${ }^{54}$ Entre las circunstancias más habituales que se suelen esgrimir para la modificación del régimen de relaciones personales establecido se encuentra la mejora de la relación de los abuelos con el nieto que puede implicar por ejemplo el paso de un régimen que sólo incluya visitas a uno que incluya estancias temporales. También puede ocurrir lo contrario y que el empeoramiento de las relaciones lleve aparejada la necesidad de restringir el régimen estableciendo que se desarrolle a través de un Punto de Encuentro Familiar. El aumento de la edad del nieto puede suponer una modificación ya que es más factible que los abuelos pasen más tiempo por ejemplo con un nieto de I4 años que con un bebé de corta edad. El incumplimiento de las obligaciones del régimen de relaciones personales (horarios, inmiscuirse en las facultades de los progenitores, dejar a los menores a cargo de terceros) puede implicar, ex art. 776,, LEC, la modificación en sentido restrictivo. CoLAS ESCANDÓn, Relaciones familiares de los nietos con sus abuelos: derecho de visita, estancia, comunicación y atribución de la guarda y custodia, cit. pág. I38.

${ }^{55}$ Colas EsCANDón, Relaciones familiares de los nietos con sus abuelos: derecho de visita, estancia, comunicación $Y$ atribución de la guarda y custodia, cit. pág. I4I.

${ }^{56}$ Hay que matizar, en línea con lo señalado por Cristina Guillarte Martín-Calero, que el legislador reconoce este derecho de relación de forma autónoma o con sustantividad propia sólo para aquellos casos en los que existe una dificultad, obstaculización o impedimento por parte de los titulares de la patria potestad, de manera que deberá probarse este extremo y no fijar un régimen de comunicación y estancia de los abuelos si la intensidad de los contactos con los descendientes disminuye, en situaciones de crisis convivenciales, no por la actitud rebelde de los titulares de la patria potestad, sino a consecuencia de la nueva organización familiar tras la ruptura (atribución de la custodia y régimen de comunicación y estancia). GUILARTE MARTín-CALERO, «El derecho de los nietos a mantener relaciones personales con sus abuelos (A propósito de la sentencia del Tribunal supremo de 20 de octubre de 20II)»,cit. pág. 5I. 
suponer la suspensión del derecho de visitas de los padres ${ }^{57}$. A través de este concepto jurídico de justa causa, de difícil delimitación, se pueden abarcar todas las relaciones negativas para el menor en un sentido actual ${ }^{8}$. De esta manera podemos concebir in abstracto varias justas causas para la negación ${ }^{59}$. Por ejemplo, el hecho de que el abuelo haya sido condenado por delito contra la persona del hijo o nieto, el haberles negado alimentos, el haber sido privado de la patria potestad por incumplimiento grave de los deberes paternos, el deliberado ánimo de influir en los aspectos que forman parte de la patria potestad de los progenitores, las situaciones de alcoholismo o drogodependencia de los abuelos o de personas de su entorno, el padecimiento de una enfermedad infecciosa que pueda transmitirse al nieto por los abuelos, el padecimiento de una enfermedad o deficiencia que requiera un cuidado especial para el que los abuelos no están preparados, o sencillamente, el hecho de que el menor haya sido adoptado por un tercero, lo que obliga a $\mathrm{su}$ inserción en la nueva familia. Como es lógico, en algunos de estos supuestos, que no agotan necesariamente el contenido de la justa causa, habrá que atender a las circunstancias concurrentes pudiendo en ocasiones suponer una mera suspensión del régimen o una modificación del mismo ${ }^{60}$. Mientras que, in concreto, la jurisprudencia del Tribunal Supremo no arroja mucha luz sobre qué haya de entenderse por justas causas aunque sí ha declarado reiteradamente que no tienen esa consideración las rencillas personales o aun la existencia de relaciones tensas o de animadversión entre progenitores, o alguno de ellos, y los abuelos ${ }^{6 \mathrm{I}}$.

Cristina Guilarte califica la postura de la jurisprudencia en este punto como prudente, recordando que aunque la falta de relación o la relación tensa e incluso hostil no determinan la negativa del juzgador la realidad demuestra que el grado de conflicto o las razones para la falta de relación influyen decisivamente en la decisión última que niega el derecho de relación con los abuelos o adapta el régimen de comunicación a la situación de conflicto entre las partes. La mencionada autora distingue dos grupos de supuestos: de un lado, el fallecimiento o suspensión del régimen de comunicación y estancia de uno de los titulares de la patria potestad; de otro lado, el conflicto de los abuelos y ambos titulares de la patria potestad ${ }^{62}$. En el primer grupo de supuestos puede apreciarse una línea jurisprudencial claramente favorable al mantenimiento de la relación personal con los abuelos en casos en los que no pueda mantenerse de forma directa con el padre/madre por

57 CARballo Fidalgo, M., «El derecho de visita de los abuelos y la atribución de la guarda de sus nietos tras la ley 42/2003, de 2I de noviembre. Aspectos sustantivos y procesales», cit. pág.5I.

${ }^{58}$ Verdera IzQuierdo, B., «Situación actual del derecho de visita a las abuelos», cit, pág.9.

59 BERROCAL LANZAROT, «Reflexiones sobre las relaciones familiares entre abuelos y nietos tras la nueva Ley 42/2003, de 2I de noviembre», cit. pág. io6; CARballo Fidalgo, M., «El derecho de visita de los abuelos y la atribución de la guarda de sus nietos tras la ley 42/2003, de 2I de noviembre. Aspectos sustantivos y

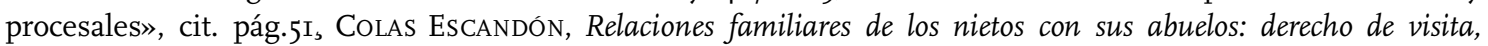
estancia, comunicación y atribución de la guarda y custodia, cit. págs. I4I y ss.

${ }^{60}$ Ana Isabel Berrocal Lanzarot, realiza una puntualización muy interesante que debe ser tenida en cuenta en relación con este derecho a las relaciones personales al hilo de algunas de las recientes reformas introducidas en materia de derecho de familia como la Ley I3/2005 de I de julio, por la que se modifica el Código Civil en materia de derecho a contraer matrimonio (BOE I57, 2 julio de 2005) y que permite el matrimonio entre personas del mismo sexo. Para la autora «tanto la orientación sexual de los abuelos/as, como el hecho actualmente reconocido de haber contraído matrimonio con otra persona del mismo sexo no se puede considerar justa causa» que impida el derecho de los abuelos a relacionarse con sus nietos ( $\cdots)$ En nuestro ordenamiento, con la actual Ley 13/2005, encajaría la posibilidad de relación de éste con estos abuelos en sentido sociológico, aunque sean personas del mismo sexo que su abuelo/a, pues son cónyuges del mismo; si bien lo harían en su consideración como allegados», BERROCAL LANZAROT, «Reflexiones sobre las relaciones familiares entre abuelos y nietos tras la nueva Ley 42/2003, de 2I de noviembre», cit. pág. Io8.

${ }^{6}$ SSTS de 7 de abril de I994, de II de junio de I996, 20 de septiembre de 2002, 28 de junio de 2005, 27 de julio de 2009 .

\footnotetext{
${ }^{62}$ GuILARTE MARTín-CALERO, «El derecho de los nietos a mantener relaciones personales con sus abuelos (A propósito de la sentencia del Tribunal supremo de 20 de octubre de 20II)»,, cit. pág.54-55.
} 
fallecimiento o por haber sido suspendido el régimen de comunicación o estancia (progenitor en régimen de privación de libertad o ausente en su relación paterno filial) ${ }^{63}$. El segundo grupo de casos es más controvertido y las decisiones varían en función del origen del conflicto, de su intensidad e incidencia en el menor aunque puede concluirse que mayoritariamente se inclinan por el reconocimiento del derecho de relacionarse de los nietos con los abuelos si bien limitado en cuanto al tiempo, el lugar y supervisado por especialistas. En general, desde el punto de vista de la psicología en los casos de visitas entre padres e hijos se prioriza la trascendencia del vínculo, prevaleciendo su promoción y continuidad teniendo en cuanta las medidas que puedan mitigar los efectos del conflicto aunque éste permanezca. Mientras que en el supuesto de las relaciones entre los nietos o nietas y sus abuelos y abuelas el abordaje de la problemática familiar debe ser previo al establecimiento del régimen de relaciones personales ya que la prioridad es proteger al menor del enfrentamiento entre adultos ${ }^{64}$. A la luz de estos criterios, el derecho a las relaciones personales con los abuelos está reconocido en el ordenamiento jurídico español pero, como es lógico, no se configura de la misma manera ni alcanza la misma relevancia que el régimen de visitas de los progenitores no custodios.

En cuanto a la extinción del derecho, al tener naturaleza temporal se produce por las siguientes causas: mayoría de edad, emancipación o recuperación de la plena capacidad en caso de incapacitación del nieto o nieta (a partir de este momento será él o ella quién decida si seguir manteniendo o no relaciones personales con sus abuelos), muerte o declaración de fallecimiento del nieto o nieta o de los abuelos. En este último caso, como es lógico, si fallece uno de los abuelos, el superviviente seguirá disfrutando de este derecho salvo que se vea privado judicialmente de él por la concurrencia de una justa causa.

\section{Conclusiones}

El reconocimiento del derecho a las relaciones personales entre abuelos y nietos y su plasmación en el ordenamiento jurídico español supone, entre otras cosas, la constatación de la posición de las personas mayores que son además abuelos en la familia española y, de algún modo, un reconocimiento a la importancia del papel que desempeñan. Aunque es cierto que este derecho, antes de la reforma analizada, tenía ya un cierto recorrido jurisprudencial y a pesar de que el legislador a la hora de fijar el contenido del mismo no ha realizado un gran esfuerzo de precisión, es innegable que su explicitación en el Código Civil transparenta un cambio en el seno de la familia y su estructura muy importante y que las leyes no podían dejar de reflejar.

Los abuelos -al menos muchos abuelos y abuelas- ya no son parientes ajenos al devenir cotidiano de sus nietos y nietas, sino que toman muchas veces un papel activo en la provisión de cariño y apoyo e incluso de cuidado directo. Paralelamente a la maternidad y paternidad también la abuelidad, si se nos permite el neologismo, ha cambiado paulatinamente de sentido y de significado. Los nietos son ahora -con todas las cautelas que precisa una generalización de este tipo- una fuente de satisfacción para sus abuelos, a la vez que los abuelos y abuelas son una fuente de apoyo considerable para sus nietos.

\footnotetext{
${ }^{63}$ SSTS de 7 de abril de I994, de II de junio de I996, de 28 de junio 2004 , de 27 de julio de 2008 . Esta línea favorable se mantiene también en las decisiones de los tribunales de instancia, denegándose únicamente en los casos en los que el grado de conflictividad trasciende los grados razonables, roza la violencia y afecta negativamente al menor que se opone a mantener relaciones personales con sus abuelos (SAP de Cadiz de 22 de septiembre de 20II; SAP de Alicante de 28 de junio de 20II; SAP de Alicante de II de enero de 20I2).

${ }^{6}$ Sala Berga, E., Fernandez Planas, S., Montaner Gorgoll, A., Paus Pujol, C, «El asesoramiento psicosocial en las reclamaciones judiciales de régimen de visitas entre abuelos y nietos», en RoDRIGUEZ, F.J, Bringas, C., Fariña, F., Arce, R., Bernardo, A (eds.), Psicología Jurídica, familia y victimología, Oviedo, Universidad de Oviedo, Sociedad Española de Psicología jurídica y Forense, 2008, pág I3I.
} 
Ante una situación de crisis de la pareja de progenitores del menor o ante la muerte de uno de ellos se puede llegar a producir un alejamiento entre nietos y abuelos que, en esas circunstancias difíciles para los menores, suponga un perjuicio adicional para éstos. Pero en este sufrimiento recae también sobre los propios abuelos que en algunas ocasiones, sobre todo si son los padres del cónyuge fallecido o el no custodio en una separación o divorcio, ven como son alejados de sus nietos. En cualquier caso la regulación de este derecho se contempla siempre desde la perspectiva del interés superior del menor. La ley reconoce en general el papel beneficioso de los abuelos en la vida de sus nietos y específicamente su posible rol de mediadores, de suavizadores en situaciones de ruptura de la pareja de progenitores, que los abuelos pueden adoptar. Se presupone que esas relaciones de abuelos y nietos van a ser beneficiosas para el menor y por eso se fomenta el mantenimiento de las relaciones entre abuelos y nietos que estén basadas en el amor y en el cariño.

Por eso mismo, a través de la aplicación del concepto jurídico indeterminado de justa causa como criterio de exclusión en los términos aquí analizados pueden y deben evitarse todas aquellas situaciones en los que las relaciones entre abuelos y nietos no cumple con estos parámetros. El ordenamiento jurídico español y la práxis judicial no equiparan la posición de los progenitores a la de los abuelos pero reconoce y ampara las relaciones de estos últimos con sus nietos -e incluso las relaciones de otros parientes y allegados con los menores en otros términos- por considerarlas valiosas sobre todo para el armonioso e integral desarrollo de los menor en línea con lo propugnado en la Convención de las Naciones Unidas sobre los Derechos del Niño de I989 que establece, entre otras cosas, el deber de los Estados de respetar el papel de los miembros de la familia ampliada y de tener en cuenta el derecho del niño a las relaciones familiares (art.8).

Las personas que son hoy niños y niñas en nuestra sociedad tienen, en términos generales, una relación mucho más frecuente y estrecha con sus abuelos y abuelas y, es de suponer, que también más afectiva y cercana que en épocas anteriores. Evidentemente esto no es siempre así ya que cualquier idealización tópica de la familia choca frente a la tozuda realidad que la muestra, en ocasiones, como escenario de duras situaciones de abuso o maltrato y, con mucha mayor frecuencia, como un escenario de conflicto interpersonal. En cualquier caso parece una cuestión de justicia que siempre en interés de los y las menores lo mismo que los hijos e hijas de padres divorciados o separados es deseable que mantengan una buena relación con ambos progenitores ocurra lo mismo respecto de sus abuelos en situaciones de grave conflicto, muerte de uno de los progenitores o ruptura del matrimonio o la pareja. Así lo pide la nueva dimensión social que con el tiempo han alcanzado las relaciones entre abuelos y nietos y por eso mismo, aunque sea de manera tímida y algo imprecisa, lo recoge explícitamente la ley aplicable.

\section{Bibliografía}

BAzo, M.T., «Relaciones familiares y solidaridad intergeneracional en las nuevas sociedades envejecidas», en Panorama Social, I5, 2012, pág. I27-142.

BAzo, M.T., «Aportaciones de las personas mayores a la sociedad. Análisis sociológico», en Revista Española de Investigaciones Sociológicas REIS, 73, I996, pág. 209-222.

BerRocal LANZAROT, A.I, «Reflexiones sobre las relaciones familiares entre abuelos y nietos tras la nueva Ley 42/2003, de 2I de noviembre» en Anuario de Derechos Humanos. vol. 6. 2005, págs. II-III.

Buz Delgado, J., Bueno Martínez, B, «Las relaciones intergeneracionales», en Portal Mayores. Lecciones de Gerontología, 66, 2006, pág. 9 (disponible en

http://www.imsersomayores.csic.es/documentos/documentos/buz-relaciones-or.pdf;fecha de consulta: 2I.I2.2OI2)

CARballo Fidalgo, M., «El derecho de visita de los abuelos y la atribución de la guarda de sus nietos tras la ley 42/2003, de 2I de noviembre. Aspectos sustantivos y procesales», en Revista de Derecho de familia, 30, 2006 , págs. $45-77$. 
Colas Escandón, A.M., Relaciones familiares de los nietos con sus abuelos: derecho de visita, estancia, comunicación $Y$ atribución de la guarda y custodia, Cizur Menor (Navarra), Thompson Aranzadi, 2005,

Corvo LóPEZ, F., «A propósito de la nueva regulación de los niños con sus abuelos en Francia y en España», en Alonso Pérez, M., Martínez Gallego, E.M., Reguero Celada J. (coords.), Protección Jurídica de los mayores, Madrid. La Ley, 2004, pág. 349-354.

De la Fuente, R., GonZÁlez, J., «Visibilidad y reconocimiento de la generación de los mayores. La importancia de los abuelos en la vida familiar», en Panorama Social, I5, 2012, pág. I59 - I64

DiAZ-AlABART, S., «El derecho de relación personal entre el menor y sus parientes y allegados (artículo i60.2 del Código Civil) », en Revista de Derecho Privado, 85, 2003, págs. 345-37I.

FinCH, J., Family obligations and social change, Cambridge, Polity Press \& B. Blackwell, I989.

Flaquer Villardebó, LL., El destino de la familia, Barcelona, Ariel, I998.

FLÓREZ LOZANO, J.A «El síndrome del cuidador». en Jano Medicina y Humanidades, 558, 2004, págs. 46- 50.

García CANTERo, G., Las relaciones familiares entre nietos y abuelos según la Ley de 21 de noviembre de 2003, Madrid, Cuadernos Civitas, 2003.

GarcíA-MorÁn, E., KueHn, Z., «Relaciones entre generaciones y mercado de trabajo. La importancia de los abuelos en la participación laboral de las madres», en Panorama Social, I5, 2012, pág.79-92.

Guijarro Morales, A., El síndrome de la abuela esclava: pandemia del siglo XXI, 2001, Granada, Grupo editorial Universitario.

Guilarte Martín-CAlero, C., «El derecho de los nietos a mantener relaciones personales con sus abuelos (A propósito de la sentencia del Tribunal supremo de 20 de octubre de 20II)», en Revista de Derecho de Familia, 56, 2012, págs. 45-57.

Henderson, T.L., Moran, P. B., «Grandparent Visitation Rights. Testing the Parameters of Parental Rights» en Journal of Family Issues, 22, 2001, pág. 619-638

Meil Landwerlin G. « La figura del abuelo en las familias españolas en la actualidad» en Portularia, 3, 2003, págs. 33-47.

NAVArro V, El subdesarrollo social de España: Causas y consecuencias, Barcelona, Anagrama, pág. I05

OsunA, M.J., «Relaciones familiares en la vejez: vínculos de los abuelos y de las abuelas con sus nietos y nietas en la infancia» en Revista Multidisciplinar de Gerontología, I6, 2006, pág. I6-25.

PARra LuCÁn, M.A., «Capacidad y estado de las personas», en Delgado EcheVerría, J. (dir.), Manual de Derecho civil aragonés, Zaragoza, Justicia de Aragón, 2007, págs. II5-I95.

PinAzo Hernandis, S., «Significado social del rol de abuelo» en Revista Multidisciplinar de Gerontología, 9, I999, págs. $169-176$.

RAdL Philipp, R ., «Transformaciones en el comportamiento en función del género en la vejez: el caso de las relaciones familiares entre abuelas, abuelos y nietas y nietos», en Papers: revista de sociología 70, 2003," pág. II7-I34.

Sala Berga, E., Fernandez Planas, S., Montaner Gorgoll, A., Paus Pujol, C, «El asesoramiento psicosocial en las reclamaciones judiciales de régimen de visitas entre abuelos y nietos», en RoDRIGUEZ, F.J, BRINGAS, C., Fariña, F., Arce, R., Bernardo, A (eds.), Psicología Jurídica, familia y victimología, Oviedo, Universidad de Oviedo, Sociedad Española de Psicología jurídica y Forense, 2008, págs I3I-I36.

ToBío, C., «Redes familiares, género y política social en España y Francia», en Política $y$ sociedad, 2, 2008, págs. 87-IO4.

Verdera IzQuierdo, B., «Situación actual del derecho de visita a las abuelos», Comunicación, I Congrés estatal sobre la defesa dels menors a las crises de parella, 2008, págs. I-I2

(disponible en http://ibdigital.uib.es/greenstone/collect/portal_social/archives/D_I2.dir/D_I2.pdf; fecha de consulta: 7-I2-20I2).

Villagrasa AlCAide, C., «La custodia compartida en España y en Cataluña: Entre deseos y realidades» en, Picontó, Novales, T., (ed.), La custodia compartida a debate, Cuadernos Bartolomé de las Casas, 56, Madrid, Dykinson, pág. 77-I00.

YAÑEZ VIVERO, $\mathrm{M}^{\mathrm{a}} \mathrm{F}$, «El derecho del menor a relacionarse con los abuelos en situaciones de ruptura familiar y desamparo», en RavetLlat Ballesté, I., Villagrasa AlCAide, C. (coords.), Los derechos de la infancia y de la adolescencia, Barcelona, Ariel, 2006, págs. I7I-I90. 